\title{
NOTES
}

\section{Synthesis of Poly(2-oxazoline) Ionene Polymer}

\author{
Shiro KobAYASHI, ${ }^{*}$ Hiroshi UYAMA, and Yutaka NARITA \\ Department of Molecular Chemistry and Engineering, Faculty of \\ Engineering, Tohoku University, Aoba, \\ Sendai 980, Japan
}

(Received September 21, 1989)

\begin{abstract}
KEY WORDS Ionene / Poly(2-oxazoline) / Multicoupling Reaction / Living Polymerization / Tertiary Diamine / Aromatic Diamine / Polyelectrolyte /
\end{abstract}

Ionene polymers having ionic groups in the polymer main chain are well known. Among them, polymeric quaternary ammonium salts 3 have been prepared by the reaction of a tertiary diamine $\mathbf{1}$ with a dihalide $\mathbf{2}$ and shown to exhibit elastomeric properties. ${ }^{1,2}$

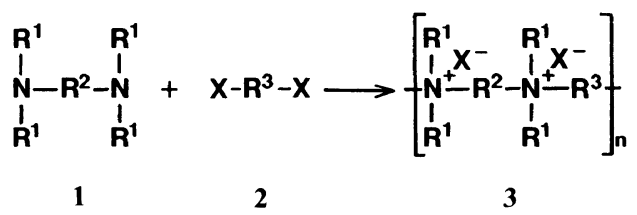

Electrophilic (cationic) ring-opening polymerization $^{3}$ of 2-alkyl-2-oxazoline ( $\mathrm{ROZO}$ ) is a versatile, convenient method to prepare linear $\operatorname{poly}\left(N\right.$-acylethylenimines) $(\mathrm{PROZO}){ }^{4}$ The polymerization of $\mathrm{ROZO}$ proceeds via living propagating species and the living end reacts quantitatively with various nucleophiles such as water and amines. ${ }^{5}$ Very recently we found that allyl-type dihalides are effective bifunctional initiators for the polymerization of ROZO giving rise to a fast initiation system. ${ }^{6}$ In using these initiators, PROZO having two living propagating species at both ends 4 can be readily obtained. This paper deals with the first synthesis of ionene polymers 5 by multicoupling reaction in one-pot between PROZO having two living ends 4 and a tertiary or aromatic diamine.

\section{EXPERIMENTAL}

\section{Materials}

Monomer, 2-methyl-2-oxazoline (MeOZO) was purified by distillation over potassium hydroxide. Other reagents and solvents were purified by distillation or recrystalization. All

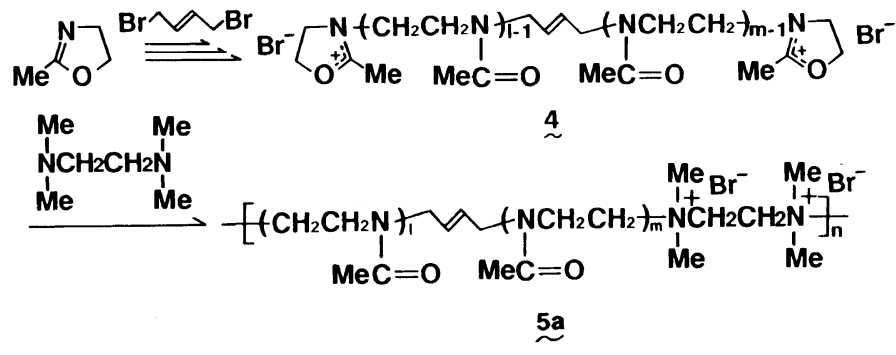

Scheme 1.

* To whom all correspondence should be addressed. 
operations were carried out under argon.

\section{Preparation of Ionene Polymer 5 Containing PROZO}

A typical run was as follows (entry 1). Under argon, a mixture of $1.07 \mathrm{~g}(5.02 \mathrm{mmol})$ of 1,4-dibromo-2-butene and $4.42 \mathrm{~g}$ (51.9 $\mathrm{mmol}$ ) of MeOZO in $20 \mathrm{ml}$ of DMF was heated at $80^{\circ} \mathrm{C}$ for $6 \mathrm{~h}$. After cooling to room temperature, $0.581 \mathrm{~g}(5.00 \mathrm{mmol})$ of $N, N, N^{\prime}, N^{\prime}$ tetramethylethylenediamine (TMEDA) was added to the mixture. The reaction mixture was then heated at $100^{\circ} \mathrm{C}$ for $2 \mathrm{~h}$ and poured into a large amount of diethyl ether. The polymeric materials were collected and dried in vacuo to give $5.76 \mathrm{~g}(95 \%$ yield $)$ of $\mathbf{5 a}$.

\section{Measurements}

${ }^{1} \mathrm{H}$ NMR spectra were recorded on a $60 \mathrm{MHz}$ JEOL FX-60Q sepctrometer or a $250 \mathrm{MHz}$ Bruker AC250T spectrometer. The reduced viscosity of polymer solutions was measured with an Ubbelohde viscometer at $25^{\circ} \mathrm{C}$.

\section{RESULTS AND DISCUSSION}

The polymerization of $\mathrm{MeOZO}$ was carried out using allyl-type dihalide, 1,4-dibromo-2butene as a bifunctional initiator at $80^{\circ} \mathrm{C}$ in

Table I. Synthesis of ionene polymer containing poly(MeOZO) 5

\begin{tabular}{cccccc}
\hline & & & \multicolumn{2}{c}{ Polymer 5 } \\
\cline { 3 - 6 } Entry & Diamine & & & \\
& & Structure & $l+m^{\mathbf{b}}$ & Yield $/ \%$ & $\eta_{\text {sp }} / c^{\mathbf{c}}$ \\
\hline 1 & TMEDA & $\mathbf{5 a}$ & 10.3 & 95 & 0.060 \\
2 & DABCO & $\mathbf{5 b}$ & 10.9 & 97 & 0.028 \\
3 & DPy & $\mathbf{5 c}$ & 10.2 & 88 & 0.040 \\
\hline
\end{tabular}

a $\mathrm{TMEDA}=N, N, N^{\prime}, N^{\prime}$-tetramethylethylenediamine; $\mathrm{DABCO}=1,4$-diazabicyclo[2.2.2. $]$ octane; $\mathrm{DPy}=4,4^{\prime}$-dipyridyl.

b Calculated from the monomer to initiator ratio.

c Measured in $1.0 \mathrm{M} \mathrm{NaBr}$ aqueous solution at $25^{\circ} \mathrm{C} ; c=0.6 \mathrm{~g} \mathrm{dl}^{-1}$.

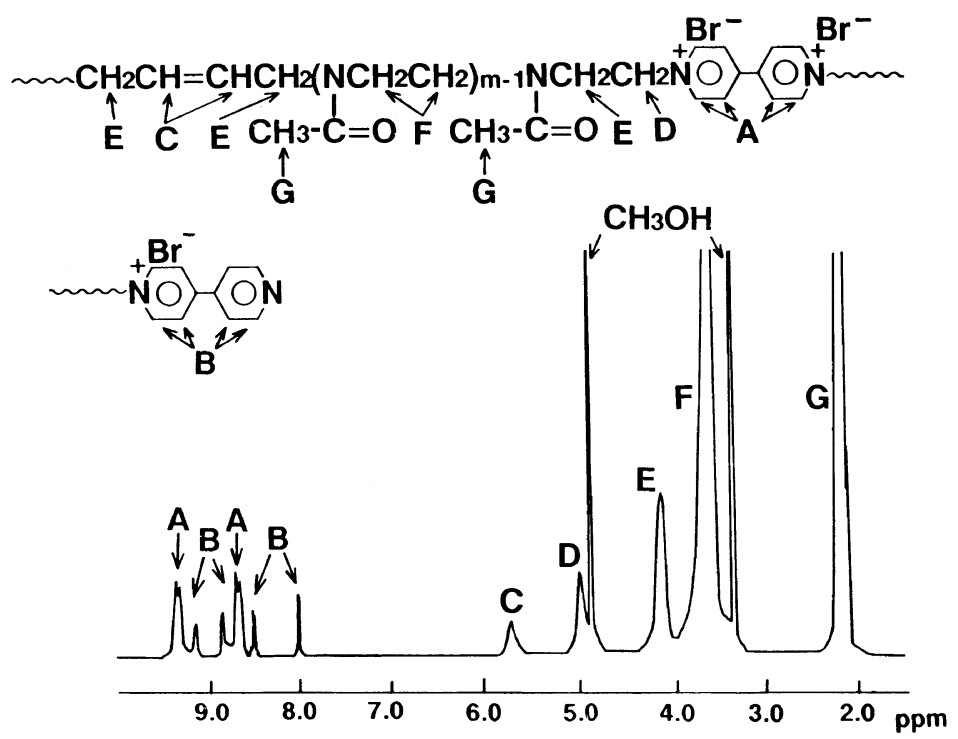

Figure 1. ${ }^{1} \mathrm{H} \mathrm{NMR}$ spectrum of $\mathbf{5} \mathbf{c}$ in $\mathrm{CD}_{3} \mathrm{OD}$. 
DMF. The living propagating species of the polymer 4 was reacted with an equimolar amount of a tertiary or aromatic diamine at $100^{\circ} \mathrm{C}$ to produce ionene polymer containing PROZO 5. The tertiary and aromatic diamines used were TMEDA, 1,4-diazabicyclo[2.2.2]octane (DABCO), and 4,4'-dipyridyl (DPy). Polymerization results are shown in Table $I$. In all cases, polymer yields were very high.

Figure 1 shows the ${ }^{1} \mathrm{H}$ NMR spectrum of $\mathbf{5 c}$ (from DPy) (entry 3). In order to assign multiplet peaks at $\delta 8.0-9.3$, two model reactions were carried out: a reaction of DPy with a five molar excess amount of methyl iodide (MeI) and an equimolar reaction between DPy and MeI. ${ }^{1} \mathrm{H}$ NMR analyses of the products obtained by the model reactions revealed that diquaternalized DPy shows two doublet peaks due to aromatic protons and monoquaternalized DPy exhibits four doublet peaks due to aromatic protons. From these observation, the multiplet peaks were assigned; the two doublet peaks $\mathrm{A}$ are due to the diquaternalized aromatic protons and the four doublet peaks B are due to the monoquaternalized aromatic protons of DPy. The ratio of integrated area of peaks $A$ and $B$ is $3: 2$, which indicates that the degree of multicoupling reaction ( $n$ value) is 2.5. The ratio of integrated area of the peaks $\mathrm{A}+\mathrm{B}$ and $\mathrm{C}$ due to $\mathrm{CH}=\mathrm{CH}$ protons derived from initiator is $4: 1$. This means that polymer $5 \mathbf{c}$ contains an equimolar amount of DPy and the initiator. Other signal assignments are given in Figure 1.

All polymers were very soluble in water, methanol and DMF, but slightly soluble in chloroform and insoluble in acetonitrile and diethyl ether. On the other hand, the homopolymer of $\mathrm{MeOZO}$ was soluble in acetonitrile and chloroform.

The viscosity behavior of solutions of $\mathbf{5 a}$ (TMEDA) (entry 1) is shown in Figure 2. The polymer 5a in water showed typical polyelectrolyte behavior; the reduced viscosity, $\eta_{\mathrm{sp}} / c$ increased remarkably with decreasing concentration of polymer (Figure 2(A)). It is known

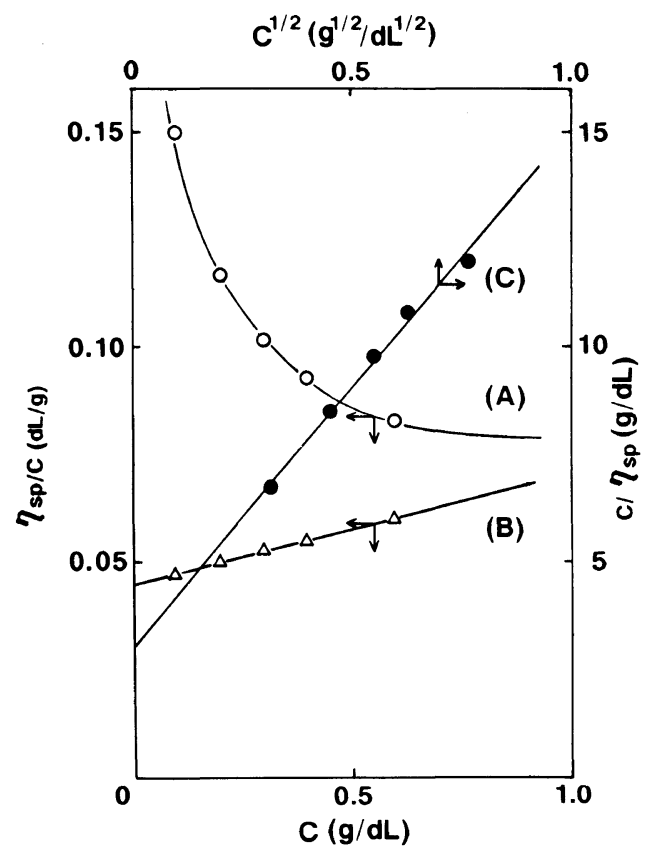

Figure 2. Reduced viscosity-polymer concentration relationships of $5 \mathbf{a}(\mathrm{A})$ in water and $(\mathrm{B})$ in $1.0 \mathrm{moll}^{-1}$ $\mathrm{NaBr}$ aqueous solution. (C) Fuoss-Strauss plots of $\mathbf{5 a}$ in water.

that various ionomers behave in a similar manner. Fuoss and Strauss proposed eq 1 for the reduced viscosity of polyelectrolyte solutions ${ }^{7}$

$$
\eta_{\mathrm{sp}} / c=A /\left(1+B C^{1 / 2}\right)
$$

where $A$ and $B$ are characteristic constants of polymer. The plots according to eq 1 show a linear relationship (Figure 2(C)), indicating the dissociation of $\mathbf{5 a}$ in water. $A$ value is $0.32 \mathrm{dlg}^{-1}$ and $\mathrm{B}$ value is $3.86 \mathrm{dl}^{1 / 2} \mathrm{~g}^{-1 / 2}$. On the other hand, plots of the reduced viscosity of $\mathbf{5 a}$ in water containing an electrolyte $(\mathrm{NaBr})$ against the polymer concentration showed linearity (Figure 2(b)). The added electrolyte suppressed the dissociation, and hence, viscosity behavior of $\mathbf{5 a}$ is similar to that of nonionic polymers.

Polymers 5 have quaternary ammonium groups and $\operatorname{poly}(N$-acetylethylenimine) (P$\mathrm{MeOZO})$ segment in the main chain. Poly- 
mers containing quaternary ammonium groups have various applications such as disinfection and antibacterial agents. ${ }^{8,9}$ On the other hand, $\mathrm{PMeOZO}$ is a polymeric analogue of $N, N$-dimethylacetamide (DMAc). DMAc is well known as an aprotic polar solvent, and hence, shows high hydrophilicity and ability to solubilize various organic polymers and inorganic compounds. Accordingly, PMeOZO has unique properties: high hydrophilicity ${ }^{10-13}$ and miscibility with commodity polymers such as poly(vinyl chloride) and poly(vinylidene fluoride). ${ }^{14} \mathrm{PMeOZO}$ does not show acute toxicity. ${ }^{10}$ Therefore polymer 5 may be used as a pharmacological active agent and compatibilizer with highly polar polymers.

Acknowledgments. S. K. acknowledges Grant-in-Aid for Scientific Research on Priority of Area of "Macromolecular Complex" (No. 63612502) from the Ministry of Education, Science, and Culture of Japan and Asahi Glass Foundation of Industry and Technology for partial support of this study.

\section{REFERENCES}

1. A. Rembaum, W. Baumgartner, and A. Eisenberg, $J$. Polym. Sci., B, 6, 159 (1968).
2. S. Kojiya, T. Ohtsuki, and S. Yamashita, Makromol. Chem., Rapid Comm., 2, 417 (1981).

3. The term "electrophilic ring-opening polymerization" has been proposed: S, Kobayashi, RingOpening Polymerization, ACS Symp. Ser., No. 286, 293 (1985); S. Kobayashi, Kobunshi, 35, 1022 (1986).

4. For recent papers on 2-oxazoline polymerizations, see: (a) S. Kobayashi and T. Saegusa, Makromol. Chem., Macromol. Symp., 1, 23 (1986). (b) P. A. Gunatillake, G. Odian, and D. A. Tomalia, Macromolecules, 21, 1556 (1988). (c) S. Kobayashi, M. Kaku, and T. Saegusa, ibid., 21, 1921 (1988). (d) G. H. Hsiue, A. X. Swammikannu, and M. H. Litt, J. Polym. Sci., Polym. Chem. Ed., 26, 3043 (1988). (e) M. Miyamoto, K. Naka, M. Tokumizu, and T. Saegusa, Macromolecules, 22, 1604 (1989).

5. S. Kobayashi, E. Masuda, S. Shoda, and Y. Shimano, Macromolecules, 22, 2878 (1989).

6. S. Kobayashi, H. Uyama, and Y. Narita, Macromolecules, in press.

7. R. M. Fuoss and U. P. Strauss, J. Polym. Sci., 3, 246 (1948).

8. M. F. Hoover, J. Macromol. Sci., Chem., 4, 1327 (1970).

9. A. Rembaum, Appl. Polym. Symp., 22, 299 (1973).

10. S. Kobayashi, T. Igarashi, Y. Moriuchi, and T. Saegusa, Macromolecules, 19, 535 (1986).

11. S. Kobayashi, S. Iijima, T. Igarashi, and T. Saegusa, Macromolecules, 20, 1729 (1987).

12. Y. Chujo, Y. Yoshifuji, K. Sada, and T. Saegusa, Macromolecules, 22, 1074 (1989).

13. Y. Chujo, E. Ihara, H. Ihara, and T. Saegusa, Macromolecules, 22, 2040 (1989).

14. S. Kobayashi, M. Kaku, and T. Saegusa, Macromolecules, 21, 334 (1988). 